\title{
Signal Enhancement for Gradient
}

Reverse-Phase High-Performance Liquid

Chromatography-Electrospray Ionization Mass

Spectrometry Analysis with Trifluoroacetic and

Other Strong Acid Modifiers by Postcolumn Addition of Propionic Acid and Isopropanol*

\author{
Frank E. Kuhlmann, Alex Apffel, Steven M. Fischer, Gerson Goldberg, \\ and Paul C. Goodley \\ Hewlett-Packard Bay Analytical Operation, Palo Alto, California, USA
}

Trifluoroacetic acid (TFA) and other volatile strong acids, used as modifiers in reverse-phase high-performance liquid chromatography, cause signal suppression for basic compounds when analyzed by electrospray ionization mass spectrometry (ESI-MS). Evidence is presented that signal suppression is caused by strong ion pairing between the TFA anion and the protonated sample cation of basic sample molecules. The ion-pairing process "masks" the protonated sample cations from the ESI-MS electric fields by rendering them "neutral." Weakly basic molecules are not suppressed by this process. The TFA signal suppression effect is independent from the well-known spray problem that electrospray has with highly aqueous solutions that contain TFA. This previously reported spray problem is caused by the high conductivity and surface tension of aqueous TFA solutions. A practical method to enhance the signal for most basic analytes in the presence of signal-suppressing volatile strong acids has been developed. The method employs postcolumn addition of a solution of $75 \%$ propionic acid and $25 \%$ isopropanol in a ratio 1:2 to the column flow. Signal enhancement is typically 10-50 times for peptides and other small basic molecules. Thus, peptide maps that use ESI-MS for detection can be performed at lower levels, with conventional columns, without the need to use capillary chromatography or reduced mass spectral resolution to achieve satisfactory sensitivity. The method may be used with similar results for heptafluorobutyric acid and hydrochloric acid. A mechanism for TFA signal suppression and signal enhancement by the foregoing method, is proposed. (J Ain Soc Mass Spectrom 1995, $6,1221-1225)$

$\mathrm{E}$ lectrospray ionization mass spectrometry (ESIMS) [1] coupled to reverse-phase high-performance liquid chromatography (RP-HPLC) has emerged as one of the most powerful techniques for the analysis of biochemical $[2,3]$ and pharmaceutical compounds $[4,5]$. The separation of complex mixtures by RP-HPLC usually involves gradient elution with modifiers to adjust the $\mathrm{pH}$ or to act as an ion-pairing agent to improve chromatographic performance. A gradient separation that uses $0.1 \%$ trifluoroacetic acid (TFA) in water and acetonitrile has become the most widely used solvent system for RP-HPLC separations of peptides and proteins because it produces excellent chromatographic peak shape for analytes, has low UV absorption at $214 \mathrm{~nm}$, and is volatile [6].

Address reprint requests to Steven $M$. Fischer, Hew lett-Packard Company, Bay Analytical Operation, 1601 California Avenue, Palo Alto, CA 94304 .

- The method described in this work is patent pending.
Unfortunately, volatile strong acids such as TFA, heptafluorobutyric acid (HFBA), and hydrochloric acid $(\mathrm{HCl})$ all cause significant signal suppression when used with electrospray ionization mass spectrometry $[4,7-10]$. The detection limits typically are reduced by up to a factor of 10 compared to $1 \%$ acetic acid $(\mathrm{AcOH})$, which is commonly used to perform ESI-MS analysis in infusion or flow injection mode (FIA) $[9,10]$. The reduced ESI-MS sensitivity when TFA is used is a significant drawback in applications where the sample amount is limited or column overloading is a problem. The most important example is peptide mapping by RP-HPLC/ESI-MS, which permits the determination of molecular weight. When collision-induced dissociation is combined with RP-HPLC/ESI-MS, sequence information on line can be generated. These techniques provide a rapid way to determine or confirm structural modifications in proteins and glycoproteins [2, 3, 11-15]. 
Since the inception of the technique, mass spectrometrists have experienced difficulty when they try to use highly aqueous solutions of TFA in ESI-MS. Both analyte signal reduction and spray instability were observed. General agreement exists that both effects are associated and are due to the high conductivity and surface tension of the solution $[2,3,8,13,16$, 17]. These two factors together during operation in a pure (unassisted nebulization) electrospray mode require the onset voltage to generate a spray to be very close to corona discharge conditions $\cdot[2,3,16,17]$. Several ways to minimize or overcome these problems have been reported. For pure electrospray, the use of capillary RP-HPLC has been shown to improve sensitivity, but cannot be considered a routine and easy-toautomate technique. Capillary RP-HPLC has been used in conjunction with electro-sharpening the electrospray needle tip $[8,16]$, the use of a surface-tension-lowering sheath liquid $[2-4,8,13-15]$, the use of dischargesuppressing sheath gas [17], or slight heating of the eluant $[2,3,18]$. Another approach has been the use of solvent systems with no [11, 15] or lower concentrations of TFA, down to $0.025 \%$ [19]. Both approaches usually result in reduced chromatographic resolution and peak tailing compared to systems using $0.1 \%$ TFA [13]. A common way to gain sensitivity without effecting chromatography is to reduce the mass spectral resolution [7], which thus sacrifices mass spectral information such as the ability to distinguish singly from multiply charged ions and accuracy of mass assignment. Finally, the introduction of pneumatically [12, $20,21]$ and ultrasonically [22] assisted nebulization allowed greater spray stability and higher flow rates at lower voltages, which thus improved signal intensities for highly aqueous TFA solutions.

In this article it will be demonstrated that when strong acid modifiers like TFA are used in RPHPLC/ESI-MS analysis, ion pairing with the strong acid anion causes a significant analyte signal reduction that is independent from the spray-generation problem. A method to overcome this signal suppression will be presented. The dramatic improvement in sensitivity will be demonstrated on a system with pneumatically assisted nebulization for a peptide map that uses a conventional $2.1-\mathrm{mm}$-i.d. high-performance liquid chromatography (HPLC) column.

\section{Experimental}

For the ESI-MS experiments a Hewlett-Packard (Palo Alto, CA) 5989B quadrupole mass spectrometer with extended mass range, high energy dynode detector, and a Hewlett-Packard 59987A atmospheric pressure ionization electrospray source with high flow nebulizer was used. These instruments were coupled to a Hewlett-Packard 1090 HPLC with a DR5 ternary solvent delivery system, autosampler, and diode array detector (DAD). The HPLC-MS system was controlled by Hewlett-Packard Chemstation software, which al- lowed full instrument control, simultaneous mass spectrometry, and UV/VIS data acquisition and data analysis.

To compare signal and signal-to-noise ratios for different solvent compositions, flow injection analyses (FIA) of a mixture of two peptides and two pharmaceuticals, with different basicities, were carried out in the selected ion monitoring mode (SIM). Val-Tyr-Val $\left(50 \mathrm{pmol} / \mu \mathrm{L} ;[\mathrm{M}+\mathrm{H}]^{+} m / z \quad 380.2\right)$, gramicidin $\mathrm{S}\left(10 \mathrm{pmol} / \mu \mathrm{L} ;[\mathrm{M}+2 \mathrm{H}]^{2+} m / z\right.$ 571.3), biotin (200 pmol $/ \mu \mathrm{L} ;[\mathrm{M}+\mathrm{H}]^{+} m / z$ 245.1), and reserpine $\left(20 \mathrm{pmol} / \mu \mathrm{L} ;[\mathrm{M}+\mathrm{H}]^{+} m / z\right.$ 609.3), all obtained from Sigma Chemical Co. (St. Louis, MO), were dissolved in acetonitrile $(50 \%) /$ water $(50 \%) /$ acetic acid $(1 \%)$.

Diphenylthiourea (Sigma; $25 \mathrm{pmol} / \mu \mathrm{L} ;[\mathrm{M}+\mathrm{H}]^{+}$ $m / z 229.1$ ) in the same solvent was injected to analyze the behavior of a neutral molecule. For each solvent composition (see Results and Discussion), four injections of $2 \mu \mathrm{L}$ were made at flow rates of 100,200, and $400 \mu \mathrm{L} / \mathrm{min}$. For the RP-HPLC/ESI-MS peptide map with and without postcolumn addition, myoglobin (Sigma Chemical Co., St. Louis, MO) was reduced, alkylated, and digested with TPCK-modified trypsin (Promega, Madison, WI) for $18 \mathrm{~h}$ at $37^{\circ} \mathrm{C}$ (substrate/ enzyme ratio 20:1). The digest (200 pmol) was separated on a Vydac (Hesperia, CA) $C_{18}$ column $(250 \times 2.1$ $\mathrm{mm}, 5 \mu \mathrm{m}, 300 \AA$ ) at a flow rate of $200 \mu \mathrm{L} / \mathrm{min}$ by using a linear gradient of $0-60 \%$ B in $60 \mathrm{~min}$ (solvent A: water $/ 0.1 \%$ TFA; solvent B: acetonitrile $/ 0.1 \%$ TFA). To prevent the entrance of digest buffer salts into the mass spectrometer, during the first $5 \mathrm{~min}$ of the run the eluant was diverted to waste by using a switching valve located after the DAD. The UV trace at $214 \mathrm{~nm}$ confirmed that no early eluting peaks were lost. After the switching valve, a Hewlett-Packard 1050 isocratic HPLC pump delivered a solution of $75 \%$ propionic acid and $25 \%$ isopropanol at $100 \mu \mathrm{L} /$ min through a tee into the flow path. Connections were made with PEEK tubing (0.005-in. i.d., $0.127 \mu \mathrm{L} / \mathrm{cm})$, a ZDV tee, and ZDV unions from Upchurch Scientific (Oak Harbor, WA). The tee was connected to the ESI needle (stainless steel, $180 \mathrm{~mm} \times 250 \mu \mathrm{m}$ o.d., $100 \mu \mathrm{m}$ i.d.). Mass spectrometry data were acquired in scan mode ( $m / z$ 200-1600, step size $0.15 \mathrm{u}$, scan rate $1.35 \mathrm{~Hz}$ ) at unit resolution. Nitrogen was used as the nebulizing (1.5 L/min, concentrically delivered) and drying (15 $\mathrm{L} / \mathrm{min}, 300^{\circ} \mathrm{C}$, countercurrent delivered) gas.

The water was deionized in a purifier (Barnstead, Dubuque, IA). Acetonitrile and isopropanol were HPLC grade (Mallinckrodt, Paris, KY). Formic and acetic acid (Sigma Chemical Co.), trifluoroacetic, butyric, and valeric acid (Aldrich, Milwaukee, WI), and propionic acid (Mallinckrodt) had purities of $>99 \%$ and were not further purified.

\section{Results and Discussion}

Researchers who used electrospray with solutions that contained TFA have noted low signal response and 
have attributed this poor signal to the high conductivity of TFA-containing solutions and high surface tension that result in an inefficient spray process. The effect of the high surface tension of water in a solution of $0.1 \%$ TFA on the analyte signal was examined by the addition of surface-tension-lowering isopropanol (IPA) in the analysis of a mixture of two peptides and two pharmaceuticals. If the surface tension was a major factor in the analyte signal reduction $[4,7-10]$, the signal should significantly improve. However, the addition of IPA results in only slight signal increase $[1.1 \times$ at $100 \mu \mathrm{L} / \mathrm{min}, 1.8 \times$ at $200 \mu \mathrm{L} / \mathrm{min}$ (see Figure la and b), and $2.5 \times$ at $400 \mu \mathrm{L} / \mathrm{min}]$, which does not account for the suppression factor of up to 10 observed when $0.1 \%$ TFA is compared with $1 \% \mathrm{AcOH}$ $[9,10]$.

Another observation is a neutral molecule such as diphenylthiourea (DPTU) shows a factor of 2 increase in response when $0.1 \%$ TFA is used compared to $1 \%$ $\mathrm{AcOH}$ (see Figure $1 \mathrm{c}$ and $d$ ). This suggests a mechanism for TFA signal suppression that is chemical in nature rather than spray dependent.

TFA is widely used for reverse-phase chromatographic separations because the anion forms ion pairs

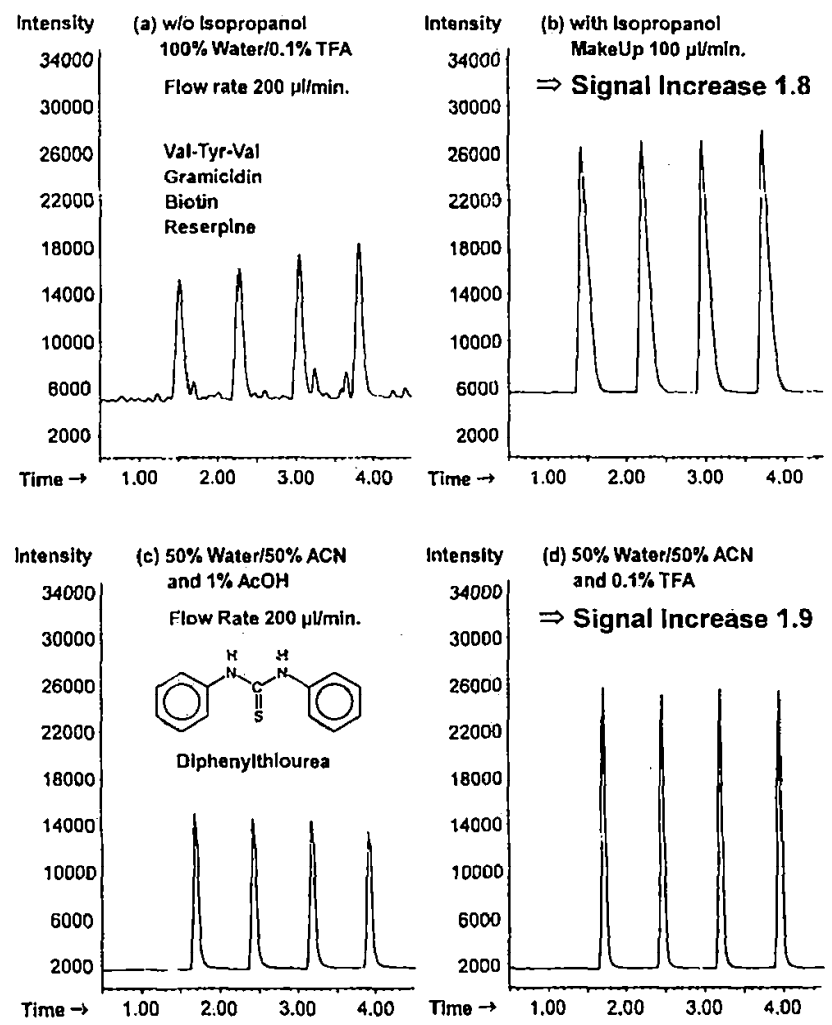

Figure 1. (a) Selected ion chromatogram (SIC) for ions $m / z$ 380.2, 571.3, 245.1, and 609.3 from four $2-\mu \mathrm{L}$ injections that contain 100 pmol Val-Tyr-Val, 20 pmol gramicidin, 400 pmol biotin, and $40 \mathrm{pmol}$ reserpine, flow injected at $200 \mu \mathrm{L} / \mathrm{min}$ in water/0.1\% TFA $(\mathrm{v} / \mathrm{v})$ and (b) at $300 \mu \mathrm{L} / \mathrm{min}$ in 67:33:0.1 water:acetonitrile:TFA $(v / v / v)$. (c) SIC for $m / z 229.1$ from four $2 \mu \mathrm{L}$ injections of $50 \mathrm{pmol}$ diphenylthiourea, How injected at 200 $\mu \mathrm{L} / \mathrm{min}$ in 50:50:1 water:acetonitrile: $\mathrm{ACOH}(\mathrm{v} / \mathrm{v} / \mathrm{v})$ and (d) at $200 \mu \mathrm{L} / \mathrm{min}$ in 50:50:0.1 wateracetonitrile:TFA (v/v/v). with basic compounds, which are further stabilized by solvation. This causes analyte molecules to appear as "neutrals" to the stationary phase, which results in longer retention times and sharper peaks on: a siliçabased reverse-phase column. The same mechanism also could prevent an ion ejection from an electrospray droplet because, in the form of a pseudo neutral soly vated ion pair, its charge is "masked" to the electric field (Figure 2, eq 5). If ion pairing causes the observed signal suppression, the signal should be restored if ion pairing with the TFA anion is eliminated.

The TFA anion is removed by adding a high concentration of a weak acid with lower volatility than TFA to the solution. The weak acid competes with the TFA anion for protons (Figure 2, eq 6). Because TFA (b.p. $72^{\circ} \mathrm{C}$ ) is more volatile than the weak acid, it will evaporate out of the droplet faster"than the weak acid. As the droplet shrinks, the acid equilibrium is driven by mass action toward deprotonation of the weak acid (Figure 2, eq 6). The weak ion pair that forms between the 'sample and the weak acid anion is reversible enough that the sample ion is ejected (Figure 2, eq 7).

To find the optimal acid and concentration to achieve maximal signal enhancement, postcolumn addition of formic, acetic, propionic, butyric, and valeric acid was examined. Final concentrations of 5, 10, 15, and $20 \%(v / v)$ in the mobile phase $[9,10]$ were tested. The experiments revealed that the signal is enhanced by the addition of the above-mentioned acids except formic acid. The signal enhancement increased in the order of acetic (b.p. $118{ }^{\circ} \mathrm{C}$ ), propionic (b.p. $141{ }^{\circ} \mathrm{C}$ ), and butyric acid (b.p. $163^{\circ} \mathrm{C}$ ) and decreased for valeric acid (b.p. $187^{\circ} \mathrm{C}$ ) below the value for acetic acid. This can be explained because butyric acid possesses the
(1) $2 \mathrm{H}_{2} \mathrm{O}$
(2) $\mathrm{H}_{2} \mathrm{O}+\mathrm{CF}_{3} \mathrm{COOH}$
$\stackrel{5 \mathrm{kV}}{\longrightarrow} \mathrm{H}_{3} \mathrm{O}^{+}+\mathrm{OH}^{-}$
(3) $\mathrm{M}+\mathrm{H}_{3} \mathrm{O}^{+}$
$=\mathrm{CF}_{3} \mathrm{COO}^{-}+\mathrm{H}_{3} \mathrm{O}^{+}$
(4) $\mathrm{H}_{2} \mathrm{O}+\mathrm{RCOOH}$
$=[\mathrm{M}+\mathrm{H}]^{+}+\mathrm{H}_{2} \mathrm{O}$
(5) $[\mathrm{M}+\mathrm{H}]^{+}+\mathrm{CF}_{3} \mathrm{COO}^{-}$
$=\mathrm{RCOO}^{-}+\mathrm{H}_{3} \mathrm{O}^{+}$
(6) $\mathrm{CF}_{3} \mathrm{COO}^{-}+\mathrm{RCOOH}$
$=\left([\mathrm{M}+\mathrm{H}]^{+} \cdot \mathrm{CF}_{3} \mathrm{COO}^{-}\right)^{ \pm \mathrm{O}^{*}}$
(7) $[M+H]^{+}+R C O O$
$\longrightarrow \mathrm{CF}_{3} \mathrm{COOH}_{(\mathrm{g})}+\mathrm{RCOO}^{-}$
$=\left([\mathrm{M}+\mathrm{H}]^{+} \cdot \mathrm{RCOO}^{-}\right)^{ \pm \mathrm{O}^{-}}$

Figure 2. Proposed mechanism for the TFA signal suppression and the signal enhancement by the addition of a weak acid: (1) Initial ESI ionization process in positive mode, that generates charge separation in the sprayed droplets. (2) Strong-acid equilibrium for TFA. (3) Sample molecules can be protonated in solution and transferred to the gas phase by the electric field. (4) Weak-acid equilibrium for propionic acid ( $\mathrm{PrOH}$ ). (5) Protonated basic sample molecules that undergo strong ion pairing with TFA anions are "masked" to the electric field and cannot be ejected. (6) In the presence of high concentrations of propionic acid, the acid com" petition between TFA and PrOH is driven by mass action toward deprotonation of PrOH, due to the higher volatility: of TFA: (7) Ion pairing with the remaining $\mathrm{PrO}^{-3}$ anions' is weak and re: versible enough so that sample ions can be ejected from the droplets. 
best balance between too little and too much volatility. If the acid that is added in substantial concentration has too high a boiling point, the droplet cannot shrink rapidly enough and only a few analyte ions will be ejected. On the other hand, if the weak acid added has too low a boiling point, the mass action that drives the acid equilibrium (Figure 2, eq 7) toward deprotonation of the weak acid will not be as effective and some signal suppression still will occur.

Propionic acid was chosen for further experiments because the terrible smell of butyric acid did not justify its slightly better performance compared to propionic acid. Different column flow rates, ratios of column-to-makeup flow, and ratios of propionic acid to isopropanol have been analyzed (data not shown) to determine the best combination. A solution of $75 \%$ propionic acid in 25\% IPA added postcolumn 1:2 with the column effluent was found to give maximal sensitivity enhancement for column flow rates of 100-400 $\mu \mathrm{L} / \mathrm{min}$. The signal enhancement obtained with this method depends on the compound, flow rate, and water content in the mobile phase. For the compound mixture analyzed, the average signal enhancement observed was $30 \times$ when solvent was $100 \%$ water; see Figure $3 a$ and $b[9,10]$. Biotin, a weakly acidic molecule $(\mathrm{pI}=3.5)$, showed the least enhancement, whereas the effect on the two peptides (Val-Tyr-Val and gramicidin S) was much greater. The results for biotin and DPTU (see Figure 1) illustrate that signal suppression by ion pairing, and thus signal enhancement by postcolumn addition of weak acids, only occurs with sufficiently basic molecules. For weakly basic (in the presence of TFA) or neutral molecules, the addition of TFA could give a stronger signal due to more efficient protonation in solution.

Figure $4 a$ shows the total ion chromatograms (200-1600 u) for a RP-HPLC/ESI-MS peptide map of a tryptic digest of myoglobin on a 2.1-mm-i.d. column at a flow rate of $200 \mu \mathrm{L} / \mathrm{min}$ with and without postcol-

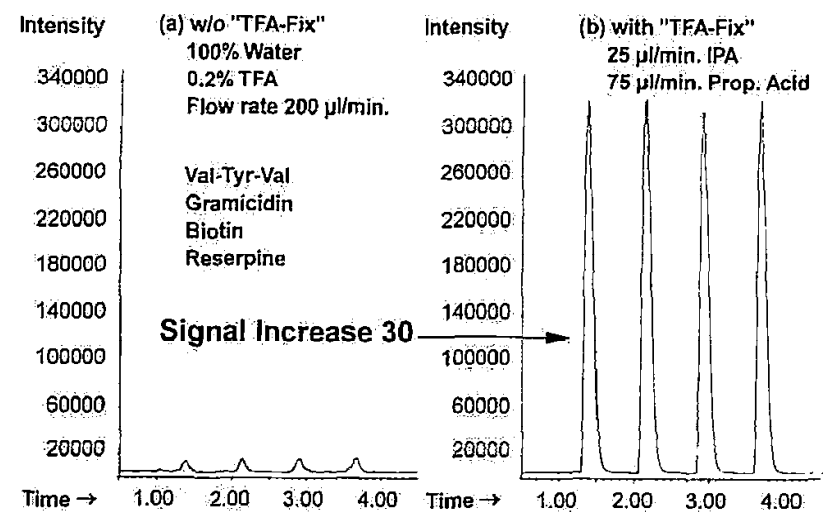

Figure 3. (a) Selected ion chromatogram for ions $m / z 380.2$, $571.3,245.1$, and 609.3 from four $2-\mu \mathrm{L}$ injections that contain 100 pmol Val-Tyr-Val, 20 pmol gramicidin, 400 pmol biotin, and 40 pmol reserpine, flow injected at $200 \mu \mathrm{L} / \mathrm{min}$ in water $/ 0.1 \%$ TFA $(\mathrm{v} / \mathrm{v})$ and $(\mathrm{b})$ at $200 \mu \mathrm{L} / \mathrm{min}$ with postcolumn addition of a solution of 75:25 PrOH:IPA (v/v) at $100 \mu \mathrm{L} / \mathrm{min}$. umn addition of propionic acid. For the four biggest peaks (marked with an "*"), which barely can be seen without the use of postcolumn propionic acid (lower trace), the signal enhancement is $40-75$ times. This degree of signal enhancement has been observed for peptide maps of other proteins (data not shown). The enhancement is greater than the signal suppression observed when $0.1 \%$ TFA is compared with $1 \% \mathrm{AcOH}$. This can be explained by the fact that $1 \% \mathrm{AcOH}$ concentration is insufficient to supply enough protons for effective protonation of peptides in the electrospray process.

Because of the surface-tension-lowering effect of both propionic acid and isopropanol, this method also eliminates the slight signal roll-off of $2 \times$ observed when $50 \%$ water is compared to $100 \%$ water content in
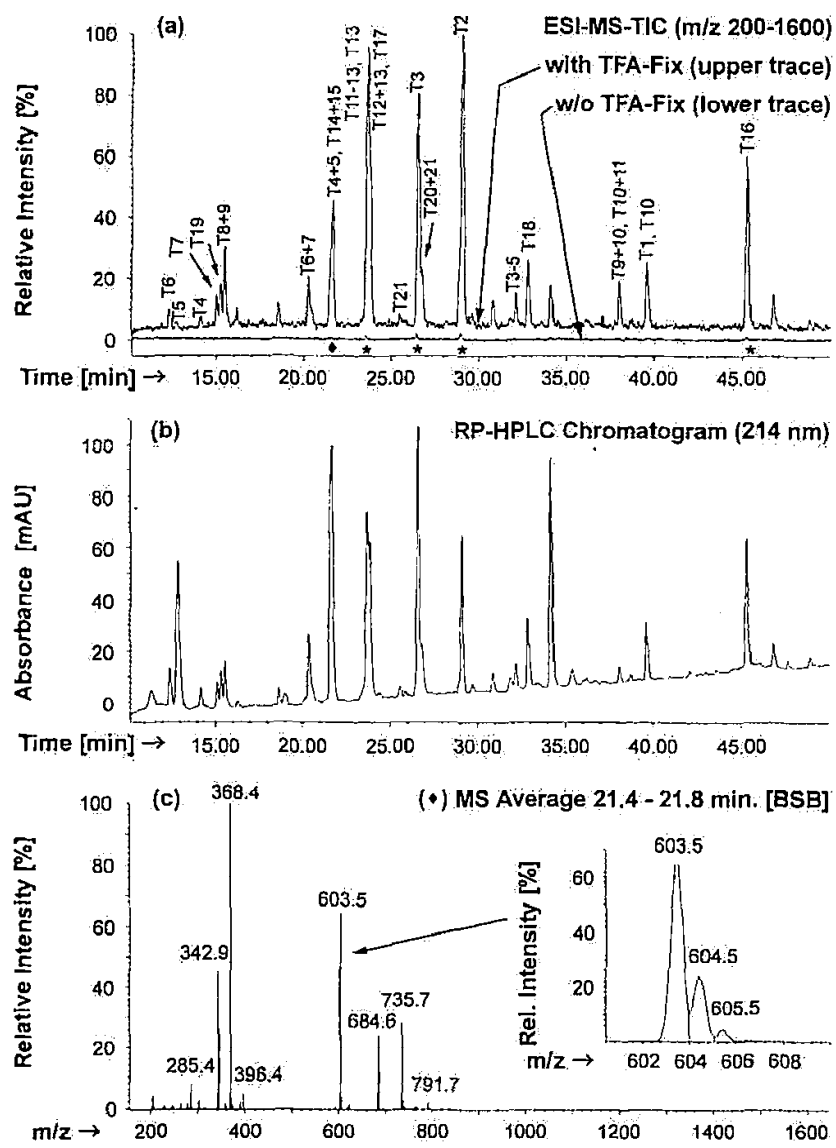

Figure 4. RP-HPLC/ESI-MS tryptic map of myoglobin (200 pmol) on a $2.1-\mathrm{mm}-\mathrm{i} . \mathrm{d} . \mathrm{C}_{-18}$ column at a column flow rate of 200 $\mu \mathrm{L} / \mathrm{min}$, running a gradient of $0-60 \% \mathrm{~B}$ in $60 \mathrm{~min}$ (solvent $\mathrm{A}$ : water $/ 0.1 \%$ TFA $(v / v)$; solvent $B$ : acetonitrile $/ 0.1 \%$ TFA). (a) Mass spectrometry total ion chromatogram (MS-TIC; $m / z$ 200-1600, step size $0.15 \mathrm{u}$, scan rate $1.35 \mathrm{~Hz}$, unit resolution) without postcolumn addition of propionic acid (lower trace) and with postcolumn addition of a solution of 75:25 PrOH:IPA (v/v) at $100 \mu \mathrm{L} / \mathrm{min}$ (upper trace). No background subtraction was used here. Peak labels refer to the tryptic fragments identified from the mass spectra. (b) UV chromatogram at 214 rm, aligned to the MS-TIC (UV and MS detectors were run in series and signals were acquired simultaneously). (c) Averaged mass spectrum from 21.4-21.8 min, after background subtraction. The inset shows unit resolution for a singly charged ion at $\mathrm{m} / \mathrm{z} 603.5$ that can be explained by chymotryptic side activity. 
the effluent $[9,10]$. The method as presented works equally well for the acids HFBA and $\mathrm{HCl}$ [9]. However, as expected from the proposed mechanism (Figure 2), it does not work for mobile phase additives of low volatility such as phosphoric acid, which has been found to cause even more signal suppression than TFA [7].

Recent experiments have shown that the addition of propionic acid also enhances the signal for small proteins like cytochrome $c$ and myoglobin in infusion analysis and RP-HPLC separations (data not shown). However, the effect decreases rapidly with increasing molecular weight. For proteins, due to the greater number of protonation sites, the magnitude of the TFA signal suppression, as well as the signal recovery by the addition of propionic acid is more dependent on the sample concentration and TFA concentration than it is for smaller molecules like peptides. For example, for a $1 \mathrm{pmol} / \mu \mathrm{L}$ solution of cytochrome $c$, infused at $50 \mu \mathrm{L} / \mathrm{min}, 0.1 \%$ TFA will decrease the signal by a factor of 250 compared to $1 \% \mathrm{AcOH}$. The addition of propionic acid gives a signal recovery of sixtyfold. For larger proteins, due to the larger number of protonated sites, it is not possible to break up enough ion pairs with TFA anions to efficiently recover the signal.

The role of ion pairing of TFA anions with protonated charge sites in electrospray ionization recently was recognized also by Mirza and Chait [23]. They showed that charge neutralization by ion pairing causes a decrease in the net average charge of peptides and proteins. They noted that a large portion of the analyte ions in solution, due to the ion pairing, is not transferred to the gas phase at all. The signal suppression caused by TFA could be seen in their data, but was not discussed.

\section{Summary}

In this article, the cause of signal suppression observed for basic molecules in ESI-MS in the presence of TFA and other strong acids was examined. The data presented show that this phenomenon is independent from the problem of spray generation observed for highly conductive and aqueous eluants in pure electrospray mode, but is caused by the strong ion-pairing property of TFA. A mechanism for the TFA signal suppression was proposed and, based on it, a method to overcome the suppression was developed. This postcolumn addition method is simple to use and applicable to most basic compounds.

The greatest potential of this technique is to improve the sensitivity for peptide mapping by RPHPLC/ESI-MS. By using this method, it is possible to obtain mass spectral data, at unit mass resolution, of peptide maps on a 2.1-mm-i.d. HPLC column, that approximates the sensitivity of UV detection at 214 $\mathrm{nm}$. Unit mass resolution allows for differentiation between singly and multiply charged ions and accurate mass assignment. In addition, the increased sensi- tivity permits the use of scan rates $(1.35 \mathrm{~Hz})$ fast enough to maintain chromatographic integrity. Because the separation is done on a 2.1 -mm-i.d. column, the method is easy to automate and the effluent optionally can be split prior to the mass spectrometer to collect material for additional peptide characterization. The signal enhancement achieved is typically in the range of 50 times.

More generally, the technique will improve sensitivity for all separations of basic compounds where volatile, strong acids are used for ion pairing or $\mathrm{pH}$ control.

\section{References}

1. Whitehouse, C. M.; Dreyer, R. N.; Yamashita, M.; Fenn, J. B. Anal. Ch'm. 1985, 57, 675-679.

2. Smith, R. D.; Loo, J. A.; Edmonds, C. G.; Barinaga, C. J.; Udseth, H. R. Anal. Chemt. 1990, 62, 882-899.

3. Smith, R. D.; Loo, J. A.; Loo, R. R. O.; Busman, M.; Udseth, H. R. Mass Spectrom. Rev. 1991, 10, 359-451.

4. Parker, C. E.; Perkins, J. R.; Tomer, K. B.; Shida, Y.; O'Hara, K.; Kono, M. I. An. Soc. Mass Spectront. 1992, 3, 563-574.

5. Poon, G. K.; Bisset, G. M. F.; Mistry, P. I. Am. Soc. Mass Spectrom. 1993, 4, 588-595.

6. Winkler, G.; Wolschann, P.; Briza, P.; Heinz, F. X.; Kunz, C. J. Cliromatogr. 1985, 347, 83-88.

7. Moseley, M. A.; Jorgenson, J. W.; Shabanowitz, J.; Hunt, D. F.; Tomer, K. B. J. Am. Soc. Mass Spectrom. 1992, 3, 289-300.

8. Eshraghi, J.; Chowdhury, S. K. Anal. Chem. 1993, 65 , $3528-3533$.

9. Apffel, A.; Fischer, S.; Goldberg, G.; Goodley, P.; Kuhlmann, F. Procedings of the 42 ind ASMS Conference on Mnss SpectromeIry and Allied Topics; Chicago, IL, 1994; $\mathrm{p} 772$.

10. Goodley, P. C.; Fischer, S.; Kuhlmann, F.; Apffel, A. Poster at the 8th Sympositm of the Protein Society; San Diego, CA, July 9-13, 1994; p 85.

11. Shabanowitz, J.; Moseley, M. A.; McCormack, A.; Michel, H.; Martino, P.; Hunt, D. F.; Tomer, K. B.; Jorgenson, J. W. Procedings of the 38th ASMS Conference on Mass Spectrometry and Allit't Topics; Tucson, AZ, 1990; pp 1497-1498.

12. Huang, E. C.; Henion, J. D. Anal. Chem. 1991, 63, 732-739.

13. Griffin, P. R.; Coffman, J. A.; Hood, L. E.; Yates, J. R. Int. /. Mass Spectrom. Ion Processes 1991, 111, 131-149.

14. Mock, K.; Hail, M.; Mylchreest, I.; Zhou, J.; Johnson, K.; Jardine, 1. 1. Chromatogr. 1993, 646, 169-174.

15. Medzihradszky, K. F.; Maltby, D. A.; Hall, S. C.; Settineri, C. A.; Burlingame, A. L. I. Am. Soc. Mass Spectrom. 1994, 5. 350-358.

16. Chowdhury, S. K.; Chait, B. T. Anal. Chem. 1991, 63, 1660-1664.

17. Ikonomou, M. G.; Blades, A. T.; Kebarle, P. J. Am. Soc. Mass Spetirom. 1991, 2, 497-505.

18. Allen, M.; Lewis, 1. A. S. U.S. Patent 4,999,493, 1991.

19. Lanting, A. B. L.; Bruins, A. P.; Drenth, B. F. H.; De Jonge, K.; Ensing, K.; De Zeeuw, R. A.; Meijer, D. K. F. Biol. Mass Spectrom. 1993, 22, 226-234.

20. Bruins, A. P.; Covey, T. R.; Henion, J. D. Anal. Che'm. 1987, 59, 2642-2646.

21. Huang, E. C.; Wachs, T.; Conboy, J. J.; Henion, J. D. Anal. Chem. 1990, 62, 713A-725A.

22. Banks, J. F.; Shen, S.; Whitehouse, C. M.; Fenn, J. B. Anal. Chem. 1994, 66, 406-414.

23. Mirza, U. A.; Chait, B. T. Anal. Chem. 1994, 66, 2898-2904. 